\title{
Normal postnatal androgen production and action in isolated micropenis and isolated hypospadias
}

\author{
B A J Evans, D M Williams, I A Hughes
}

\begin{abstract}
To try and find out if a defect in androgen biosynthesis or action could be responsible for the incomplete virilisation seen in boys with isolated hypospadias and isolated micropenis, androgen receptor binding was studied in genital skin fibroblasts established from 18 boys with isolated micropenis and 19 boys with isolated hypospadias. The production of gonadotrophins and testosterone was also measured in the boys with micropenis. There was no evidence of gonadotrophin deficiency, or of a defect in testosterone biosynthesis in the boys with micropenis, and there was no evidence of a quantitative or qualitative defect of androgen binding in either group. These isolated abnormalities may be the result of transient defects in androgen synthesis or action, or both, during a critical phase of embryogenesis.
\end{abstract}

Sexual differentiation in boys follows an orderly sequence of events once the indifferent gonad has developed into a testis. This occurs early in gestation and is under the influence of a testis determining factor, the gene for which is on the short arm of the $\mathrm{Y}$ chromosome. ${ }^{12}$ Adequate testosterone biosynthesis, the onset of which is probably initially spontaneous ${ }^{3}$ and which is later controlled by placental human chorionic gonadotropin and pituitary luteinising hormone, is required to induce Wolffian duct development. Male differentiation of the external genitalia is dependent on 5 - $\alpha$-dihydrotestosterone, ${ }^{4}$ the active reduced metabolite of testosterone, and both androgens promote phallic growth during the remainder of gestation. The ultimate biological expression of androgen action in target tissues requires the presence of a specific intracellular binding protein that can mediate the effects of androgens on gene expression. 5

Defects in fetal pituitary secretion of luteinising hormone, testosterone biosynthesis, or androgen action may show themselves as inadequate virilisation of varying severity and sometimes as genital ambiguity. Isolated micropenis and hypospadias are both disorders of inadequate virilisation that are not associated with ambiguity of the genitalia. The former may be the result of congenital hypopituitarism, it may be associated with several dysmorphic syndromes, or it may have no demonstrable cause. Hypospadias is a common isolated malformation with an incidence of $0.2-0.6 \%$. $^{6}$ The defect is the result of failure of complete fusion of the urethral folds, a process mediated mainly by dihydrotestosterone. A defect in androgen biosynthesis or action may be responsible for both these conditions.

We report a study of androgen receptor binding in genital skin fibroblasts established from two groups of boys with isolated micropenis and isolated hypospadias. We also assessed the production of gonadotrophins and testosterone in the group with isolated micropenis.

\section{Patients and methods}

MICROPENIS

Eighteen boys with isolated micropenis were studied. Their ages at the time of study ranged from $4 \cdot 1$ to 16.4 years, and eight were prepubertal with bone ages of less than 10 years. The remaining 10 were pubertal, their Tanner stages ranging from 2 to 4 . The stretched penile length was measured by the method of Schonfeld and Beebe and in each case was 2.5 SD or more below the mean value for age. ${ }^{7}$ All the boys had normal growth velocity and none was obese.

Serum samples were collected before and 30 , 60,90 , and 120 minutes after an intravenous bolus dose of $100 \mu \mathrm{g}$ luteinising hormone releasing hormone for measurement of luteinising hormone and follicle stimulating hormone. Each boy then received human chorionic gonadotrophin 2000 units daily intramuscularly for three days. A blood sample was collected on the fourth day for measurement of plasma testosterone concentration. A $2 \mathrm{~mm}$ scrotal skin punch biopsy was taken under local anaesthetic to establish genital skin fibroblasts in culture for studies of androgen receptors. Informed parental consent (and where appropriate that of the child) was obtained in each case.

\section{HYPOSPADIAS}

Nineteen boys with isolated hypospadias were studied when they were admitted to hospital for repair. The defects were all classified as glandular or penile. There were no other anomalies of the penis or associated genital abnormalities. A $2 \mathrm{~mm}$ foreskin biopsy was obtained at the time of surgery to establish genital skin fibroblasts in culture.

\section{METHODS}

Serum luteinising hormone and follicle stimulating hormone, and plasma testosterone concentrations were measured by radioimmunoassay. ${ }^{89}$ Bone ages were calculated by the method of Tanner and Whitehouse. ${ }^{10}$ Primary explants of skin were established in
Correspondence to: Professor Hughes.

Accepted 9 April 1991 
culture and genital skin fibroblasts were serially subcultured until enough cells were obtained for androgen receptor binding studies. Total receptor concentration, receptor binding affinity, and the effects of increased incubation temperature and prolonged androgen preincubation of cells on specific androgen receptor binding were all measured as previously described. ${ }^{11} 12$

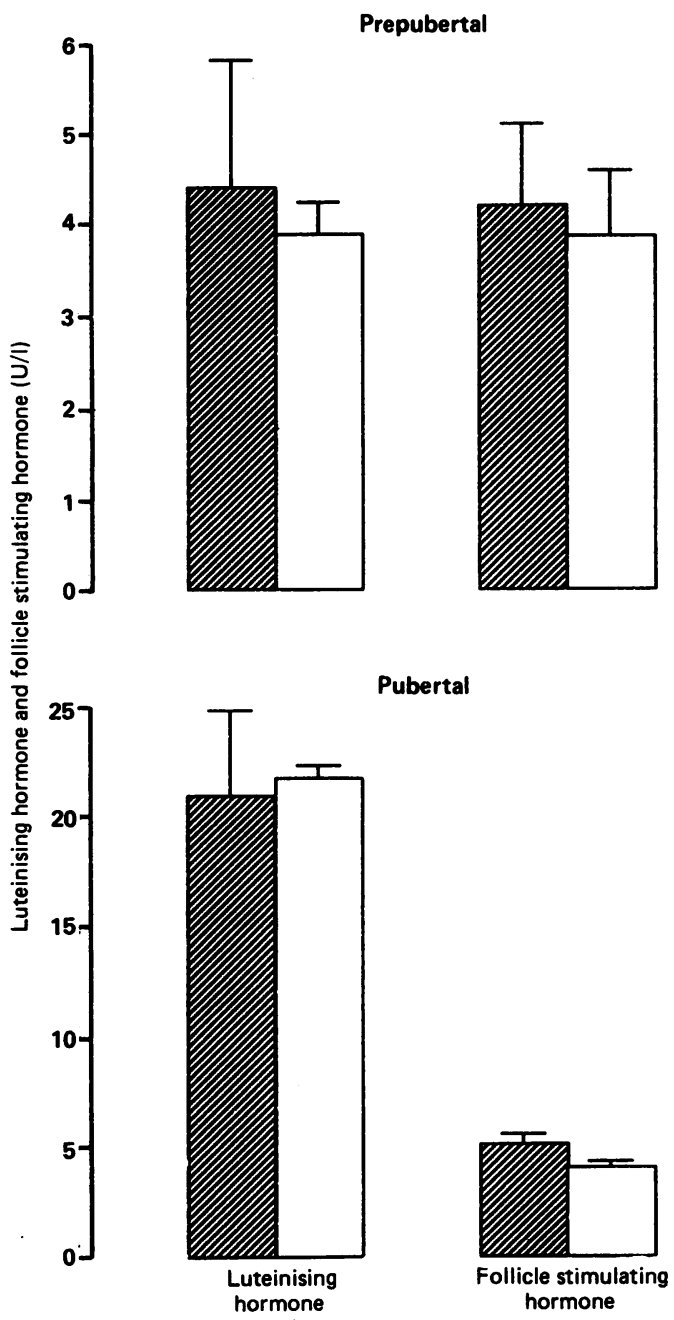

Figure 1 Mean (SEM) peak luteinising hormone and follicle stimulating hormone responses to acute stimulation with luteinising hormone releasing hormone in 18 boys with isolated micropenis. The open bars indicate the response in normal boys (adapted from Hughes ${ }^{13}$ ).
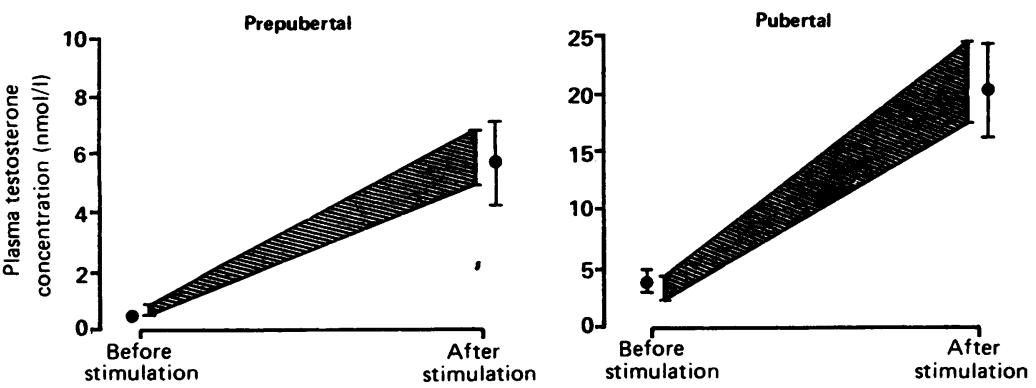

Figure 2 Mean (SEM) plasma testosterone response to stimulation with human chorionic gonadotrophin in 18 boys with isolated micropenis. The shaded area represents mean (SEM) values from normal boys (adapted from Winter et al. ${ }^{14}$ )
Results

The mean (SEM) peak luteinising hormone and follicle stimulating hormone responses to acute stimulation with luteinising hormone releasing hormone in isolated micropenis are shown in fig 1 . There were no significant differences in responses between normal boys $(n=22)$ and either pubertal or prepubertal boys with micropenis. The testosterone response to short term stimulation with human chorionic gonadotrophin was measured in the same group of boys (fig 2). The mean (SEM) peak plasma testosterone concentration in prepubertal and pubertal boys was $5 \cdot 7(1 \cdot 4)$ and $20.3(4.0)$ $\mathrm{nmol} / \mathrm{l}$, respectively; this response was within the reference range for normal boys of comparable pubertal stage. ${ }^{14}$ Figure 3 and table 1 show the results of analysis of androgen receptor binding in genital skin fibroblasts. The concentration of androgen receptors and their binding affinity in both groups of boys were similar to those in normal boys. A number of boys in both groups had apparent increases in receptor concentration compared with normal controls, but there was no evidence of receptor deficiency. There was no evidence of a thermolabile receptor in any cell strain when specific receptor binding was measured after increasing the incubation temperature from $37^{\circ} \mathrm{C}$ to $40^{\circ} \mathrm{C}$

Prolonged ( 20 hours) incubation of genital skin fibroblasts with androgen causes an increase (augmentation) in specific receptor binding in normal cell strains. ${ }^{12} \mathrm{~A}$ response is defined as an augmented: basal ratio of binding of $1.4: 1$ or more (fig 4). The median response was 1.7 in the group with hypospadias and 2.05 in those with micropenis (normal median, $2 \cdot 1 ; 10$ th and 90th centiles, 1.5 and 2.0 , respectively). There was a borderline response (a ratio of $1 \cdot 3: 1$ ) in a cell strain established from one boy with hypospadias.

\section{Discussion}

Previous -studies have suggested that abnormalities of androgen production or action may be possible causative factors in patients with isolated forms of inadequate virilisation such as hypospadias. ${ }^{15-17}$ Micropenis has been described in association with pituitary insufficiency or dysmorphic syndromes, but we found no evidence of gonadotrophin deficiency in this group of boys with micropenis who were otherwise normal. Furthermore, there was no evidence of any defect in testosterone biosynthesis based on the plasma testosterone response to stimulation with human chorionic gonadotrophin.

We tried to define some defect in androgen action to explain the incomplete virilisation in boys with isolated micropenis and isolated hypospadias. Genital skin fibroblasts are a useful target tissue to study androgen action in vitro, ${ }^{18}$ but we found no evidence of a quantitative defect in either group of boys. The presence of a normal binding affinity for the receptor and the lack of thermolability of the androgen receptor complex excluded a qualitative defect in androgen binding. A recent study that examined only prepubertal boys with hypospadias also 

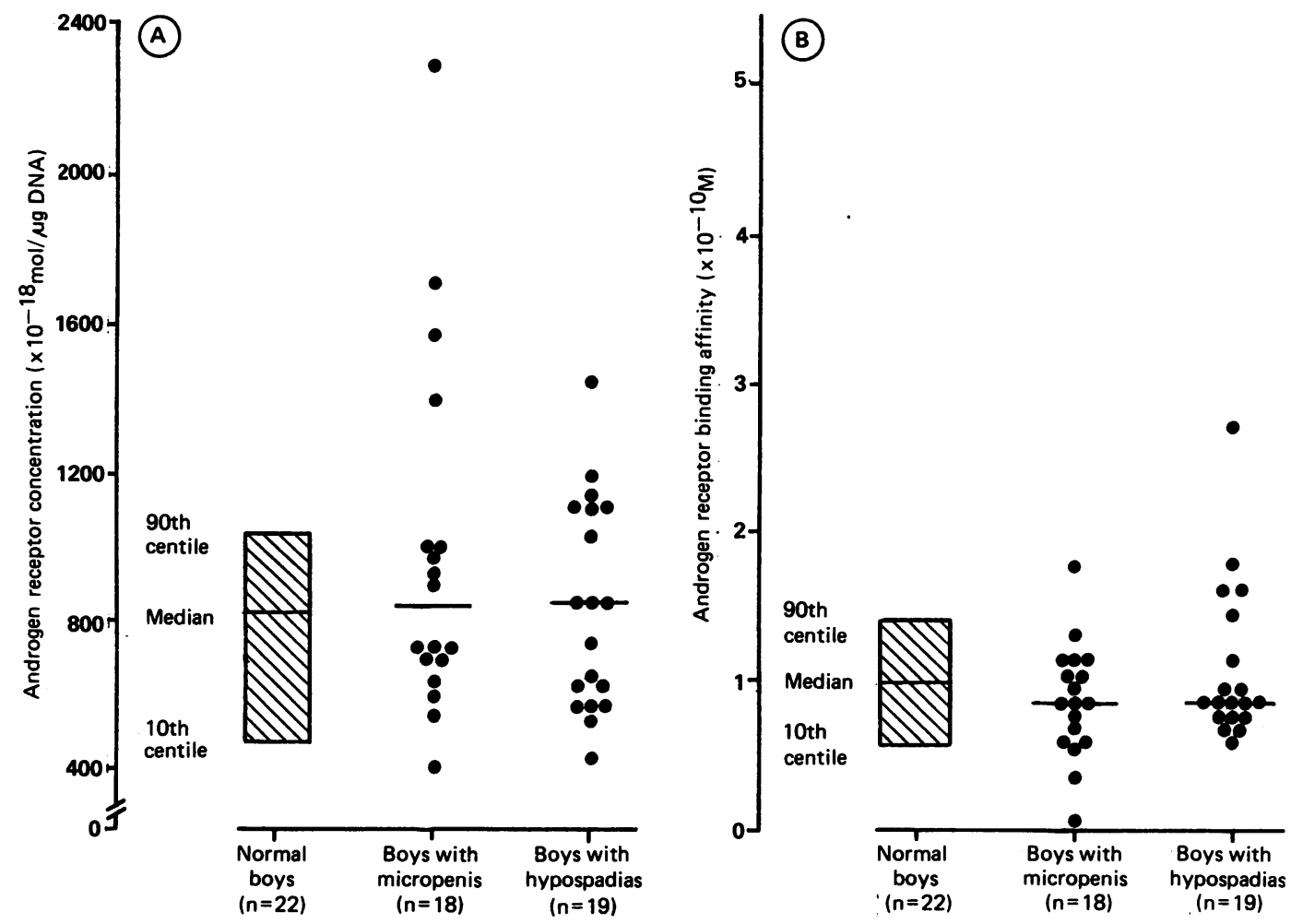

Figure 3 Androgen receptor concentrations $(A)$ and binding affinities $(B)$ in genital skin fibroblasts from 22 normal boys (median, 10th, and 90th centiles), 18 boys with isolated micropenis, and 19 with isolated hypospadias.

Androgen receptor concentration and binding affinity in boys with isolated micropenis and isolated hypospadias compared with normal boys. Normal values are expressed as median (10th and 90th centiles)

\begin{tabular}{|c|c|c|}
\hline & $\begin{array}{l}\text { Androgen receptor } \\
\text { concentration } \\
\left(\times 10^{-18} \mathrm{~mol} / \mu \mathrm{g}\right. \\
D N A)\end{array}$ & $\begin{array}{l}\text { Androgen binding } \\
\text { affinity } \\
\left(\times 10^{-10} M\right)\end{array}$ \\
\hline $\begin{array}{l}\text { Boys with isolated } \\
\text { micropenis }(n=18)\end{array}$ & 816 & $0 \cdot 86$ \\
\hline $\begin{array}{l}\text { Boys with isolated } \\
\text { hypospadias }(n=19)\end{array}$ & 834 & 0.83 \\
\hline Normal boys $(n=22)$ & $\begin{array}{l}813 \\
(471 \text { and } 1034)\end{array}$ & $\begin{array}{l}0.99 \\
(0.56 \text { and } 1.42)\end{array}$ \\
\hline
\end{tabular}

showed an apparently normal androgen receptor. ${ }^{19}$ This is in contrast to patients with a partial form of the androgen insensitivity syndrome that is characterised by a number of genital abnormalities including micropenis with chordee, perineoscrotal hypospadias, a bifid scrotum, and undescended testes. Both quantitative and qualitative defects of the androgen receptor have been described in these patients. ${ }^{11} 12 \mathrm{~A}$ recent survey of 70 patients with this syndrome reported a defect in androgen production or action in more than $20 \%$ of cases. $^{20}$

We have reported the use of androgen induced augmentation of specific receptor binding in genital skin fibroblasts from patients with micropenis and hypospadias as an in vitro marker of androgen action. The response was normal in each case. The results may provide a useful biological marker of the androgen response in vivo in those patients who require a course of androgens to facilitate repair of hypospadias by prior growth of the penis.

The cause of the defect in isolated micropenis

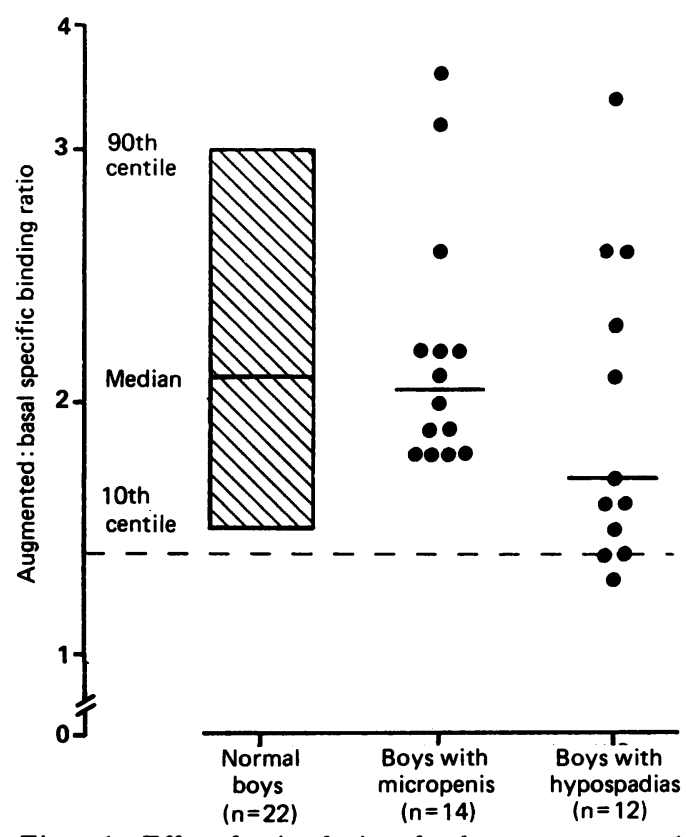

Figure 4 Effect of preincubation of androgen on augmented specific binding activity in 22 normal boys, 14 boys with isolated micropenis, and 12 with isolated hypospadias. A response was defined as an augmented basal ratio of $\geqslant 1 \cdot 4: 1$ (indicated by the broken line).

and isolated simple hypospadias remains unknown. The more severe and familial forms of hypospadias possibly represent one end of a range of phenotypic expression of the androgen insensitivity syndrome. Now that the gene for the androgen receptor has been cloned, ${ }^{21}$ it is possible that molecular genetic analysis may show some defect in this subgroup of patients. It is likely, however, that most of these boys 
have an isolated genital abnormality that has resulted from some subtle defect, perhaps in the timing of adequate androgen production or action during fetal life.

This work was supported by grants from The Medical Research Council, the Wellcome Trust, and Action Research for the Crippled Child. Mr J Lari, consultant paediatric surgeon, kindly provided foreskin biopsy samples from the patients with hypospadias.

1 Page DC, Mosher R, Simpson EM, et al. The sex determining region of the human $\mathrm{Y}$ chromosome encodes a finger protein. Cell 1987;51:1091-1104.

2 Sinclair AH, Berta P, Palmer MS, et al. A gene from the human sex-determining region encodes a protein with homology to a conserved DNA-binding motif. Nature homology to a

3 George FW, Simpson ER, Milewitch L, Wilson JD. Studies on the regulation of the onset of steroid hormone biosynthesis in fetal rabbit gonads. Endocrinology 1979;105: $1100-6$.

4 Siiteri PK, Wilson JD. Testosterone formation and metabolism during male sexual differentiation in the human embryo. f Clin Endocrinol Metab 1974;38:113-25.

King RJB. Structure and function of steroid receptors. f Endocrinol 1987;114:341-9.

6 Roberts CJ, Lloyd S. Observations on the epidemiology of simple hypospadias. BMF 1973;i:768-70.

7 Schonfeld WA, Beebe GW. Normal growth and variation in the male genitalia from birth to maturity. Am $\mathcal{f}$ Dis Child 1942;64:759-77.

8 Ferguson KM, Hayes M, Jeffcoate SL. A standardised multicentre procedure for plasma gonadotrophin radioimmunoassay. Ann Clin Biochem 1982;19:358-69.
9 Dyas J, Reed GF, Riad Fahmy D. A simple robust assay for testosterone in male plasma using $I^{125}$ radioligand and a solid phase separation technique. Ann Clin Biochem 1979;

Tanner JM, Whitehouse RH. Clinical longitudinal standards for height, weight, height velocity, weight velocity and for height, weight, height velocity, weight velocit

11 Evans BAJ, Jones TR, Hughes IA. Studies of the androgen receptor in dispersed fibroblasts: investigation of patients receptor in dispersed fibroblasts: investigation of patients with andr.

12 Evans BAJ, Hughes IA. Augmentation of androgen receptor binding in vitro: studies in normals and patients with androgen insensitivity. Clin Endocrinol 1985;23:567-77.

13 Hughes IA. Handbook of endocrine investigations in children. London: Butterworth, 1989.

14 Winter JSD, Taraska S, Faiman C. The hormonal response to HCG stimulation in male children and adolescents. 7 Clin Endocrinol Metab 1972;34:348-53.

15 Svensson J, Snochowski M. Androgen receptor levels in preputial skin from boys with hypospadias. $\mathcal{F}$ Clin Endocrinol Metab 1979;49:340-45.

16 Schweikert HU, Knauf W, Romalo G, Holler W, Bidlingmaier $F$, Knorr D. Androgen binding in cultured human fibroblasts from patients with idiopathic hypospadias. froblasts from patients with id
Horm Metab Res 1987;19:497-501.

17 Amrhein JA, Meyer WJ, Danish RK, Migeon CJ. Studies of androgen production and binding in 13 male pseudohermaphrodites and 13 males with micropenis. F Clin Endocrinol Metab 1977;45:732-8.

18 Hughes IA, Evans BAJ. The fibroblast as a model for states of androgen resistance. Clin Endocrinol 1988;28:565-79.

19 Terakawa T, Shima H, Yabumoto H, Koyama K, Ikoma F. Androgen receptor levels in patients with isolated hypospadias. Acta Paediatr Scand 1990;123:24-9.

20 Williams DM, Evans BAJ, Hughes IA. A clinical and biochemical analysis of 68 patients with the partial androgen insensitivity syndrome. Horm Res 1990;33(suppl 3):210.

21 Lubahn DB, Joseph DR, Sullivan PM, Huntington FW, French FS, Wilson EM. Cloning of human androgen French FS, Wilson EM. Cloning of human androgen receptor complementary DNA and

More evidence on sleeping position and SIDS

Doctors and nurses instinctively avoid the supine position in anaesthetised or otherwise neurologically incompetent patients. Babies are neurologically incompetent compared with adults and health workers might therefore have an aversion to placing them supine. Despite that the evidence that SIDS is more common in babies who habitually sleep prone has steadily accumulated. ${ }^{1}$

A team in Tasmania (Terence Dwyer and colleagues, Lancet 1991;337:1244-7) has performed both a prospective cohort study and a retrospective case-control study. In the prospective study information about the baby's usual sleeping position was obtained at a home visit at the age of 1 month. Of 15 babies who were later SIDS victims nine $(60 \%)$ usually slept prone at one month whereas 837 of $2592(32 \%)$ other babies did so. The relative risk for usual prone sleeping position and SIDS was $3 \cdot 12(95 \%$ confidence interval.1 18 to $8 \cdot 29$ ). Using multivariate analysis to compare the 15 SIDS victims and 116 controls matched for maternal age, birth weight, availability for interview, and month of birth the odds ratio was $4 \cdot 47(1 \cdot 30-15 \cdot 43)$.

In the retrospective case-control study two matched controls were chosen for each SIDS victim. Sixty seven per cent of SIDS cases and $37 \%$ of controls had been nursed prone giving an odds ratio of $3 \cdot 45(1 \cdot 59-7 \cdot 49)$.

The authors call for a prospective randomised trial, I think unrealistically. I can't see parents being willing to enter such a trial in view of the evidence already avaliable. I know which group I'd put my baby into. It seems to me that the evidence is strong enough for action.

ARCHIVIST

1 Engleberts AC, de Jonge GA. Choice of sleeping position for infants: possible association with cot death. Arch Dis Child 1990;65:462-7. 